\title{
Slot Antenna for Wireless Temperature Measurement Systems
}

\author{
Acar, Öncel; Jakobsen, Kaj Bjarne
}

Published in:

Proceedings of EuCAP 2016

Publication date:

2016

Document Version

Peer reviewed version

Link back to DTU Orbit

Citation (APA):

Acar, Ö., \& Jakobsen, K. B. (2016). Slot Antenna for Wireless Temperature Measurement Systems. In Proceedings of EUCAP 2016 IEEE.

\section{General rights}

Copyright and moral rights for the publications made accessible in the public portal are retained by the authors and/or other copyright owners and it is a condition of accessing publications that users recognise and abide by the legal requirements associated with these rights.

- Users may download and print one copy of any publication from the public portal for the purpose of private study or research.

- You may not further distribute the material or use it for any profit-making activity or commercial gain

- You may freely distribute the URL identifying the publication in the public portal

If you believe that this document breaches copyright please contact us providing details, and we will remove access to the work immediately and investigate your claim. 


\title{
Slot Antenna for Wireless Temperature Measurement Systems
}

\author{
Öncel Acar and Kaj B. Jakobsen \\ oncac@elektro.dtu.dk, kbjeelektro.dtu.dk
}

Department of Electrical Engineering, Electromagnetic Systems, Technical University of Denmark, Ørsteds Plads, Building 348, DK-2800 Kgs. Lyngby, Denmark

\begin{abstract}
This paper presents a novel clover-slot antenna for a surface-acoustic-wave sensor based wireless temperature measurement system. The slot is described by a parametric locus curve that has the shape of a clover. The antenna is operated at high temperatures, in rough environments, and has a $43 \%$ fractional bandwidth at the $2.4 \mathrm{GHz}$ ISM-band. The slot antenna has been optimized for excitation by a passive chip soldered onto it. Measurement results are compared with simulation results and show good agreements.
\end{abstract}

Index Terms-high temperature, temperature sensor, rough environment, wireless sensor.

\section{INTRODUCTION}

Slot antennas are attractive due to their good radiation efficiency, small size, light weight, and low cost. Consequently, numerous designs have evolved [1]-[15]. Being mostly planar structures, which are typically printed on circuit boards, slot antennas can be fed by microstrip transmission lines or coplanar waveguides in a straight forward way. This makes them easily suited for small sized applications where the antenna is permitted to lie on the same PCB as the circuitry it is coupled to. The omnidirectional radiation pattern typically possessed by slot antennas, combined with the possibility of size reduction, has made them attractive for mobile communications and GPS systems also. Modified geometries have yielded wideand ultra wide-band designs, making slot antennas suitable for microwave imaging systems as well. The freedom in geometry has formed the basis for multi-band designs, promoting their use in all-in-one antennas, i.e., when a single antenna is to be designed, e.g., a hand-held device, to cover a combination or all of the GSM, GPS, WLAN, and WiMAX bands. In addition to these are temperature-measurement systems, RFID tags and readers.

In this paper the design of an optimal slot antenna to be used as the communication front end of a temperature-measurement system that operates at the $2.4 \mathrm{GHz}$ ISM band is presented. The final system will be a small pack that includes a SAW temperature sensor right besides the antenna. The system is to be mounted on a container, and operated on board a ship in the engine compartment. Given the scenario, the design constraints, as well as several simplifications to these, can be inferred. The operating environment assures that there will be strong reflections from the metallic walls, containers and other

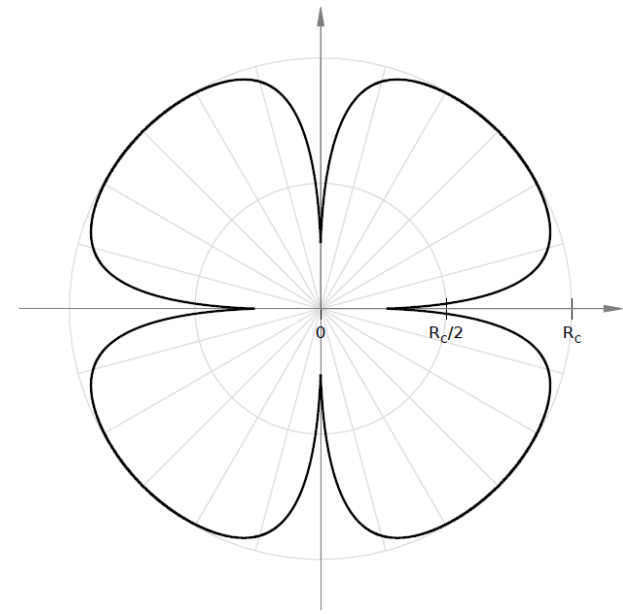

Fig. 1. The clover curve, as described by Eq. 1 and plotted for $E F=5$ and $L S A=0.52 \pi$.

structures in the neighborhood of the antenna. This means that neither the radiation pattern nor the polarization needs to be prioritized as a design constraint. Instead, the primary concern now becomes to design the antenna to be robust such that it can maintains its operation within acceptable limits despite of liquid spills (typically oil) and high temperature. Mechanical protection will be provided by a metallic ring surrounding the antenna, which will also be used to screw it onto the container surface. The oil is a dielectric material, which means that the wavelengths of the electromagnetic waves are smaller in oil. Thus, when the antenna is immersed in oil, it will become electrically larger [16]. This translates into a down shift in the operating frequency of the antenna. In order to handle this, the design must cover a wide enough band to compensate for the frequency shift. On the other hand, the high temperature might both change the electrical properties of the materials and tend to destroy the structure due to burning, decomposition, melting, or copper peeling. Therefore, the substrate choice requires attention to both temperature resistance and temperature stability. Apart from these major constraints, efficiency and the possibility to obtain a good power match are still valid restrictions. The simulated and measured reflection coefficient $\left|S_{11}\right|$ and radiation patterns of the novel type of slot antenna is presented. 


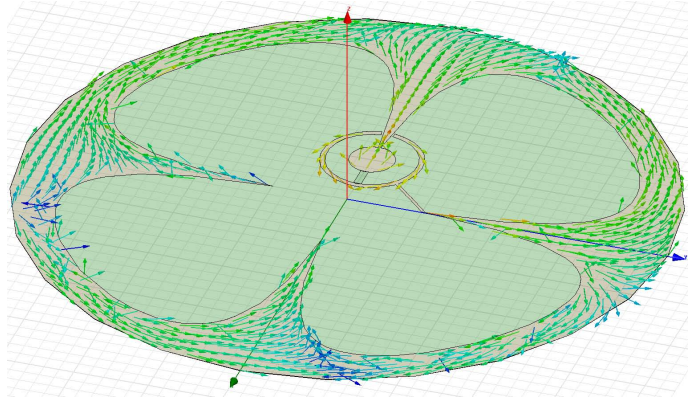

Fig. 2. The HFSS model with simulated surface current distribution on the designed clover slot antenna.

\section{DESIGN}

The locus of the clover slot antenna (CSA) is given by

$$
r= \begin{cases}R_{\mathrm{C}} \frac{\left.1-\mathrm{e}^{-E F \cos \left[\frac{\pi}{L S A}\left(\varphi-\frac{\pi}{4}\right)\right.}\right]}{1-\mathrm{e}^{-E F}} & \text { for } \quad 0 \leq \varphi<\frac{\pi}{2} \\ R_{\mathrm{C}} \frac{\left.1-\mathrm{e}^{-E F \cos \left[\frac{\pi}{L S A}\left(\varphi-\frac{3 \pi}{4}\right)\right.}\right]}{1-\mathrm{e}^{-E F}} & \text { for } \quad \frac{\pi}{2} \leq \varphi<\pi \\ R_{\mathrm{C}} \frac{\left.1-\mathrm{e}^{-E F \cos \left[\frac{\pi}{L S A}\left(\varphi-\frac{5 \pi}{4}\right)\right.}\right]}{1-\mathrm{e}^{-E F}} & \text { for } \quad \pi \leq \varphi<\frac{3 \pi}{2} \\ R_{\mathrm{C}} \frac{\left.1-\mathrm{e}^{-E F \cos \left[\frac{\pi}{L S A}\left(\varphi-\frac{7 \pi}{4}\right)\right.}\right]}{1-\mathrm{e}^{-E F}} & \text { for } \quad \frac{3 \pi}{2} \leq \varphi<2 \pi,\end{cases}
$$

where $R_{\mathrm{c}}$ is the clover radius, $E F$ is the edge flatness coefficient, $L S A$ is the leaf sector angle, and $\varphi$ is the polar coordinate angle. The locus described by Eq. 1 has the form of a clover and is shown in Fig.1.

The operating environment temperature is about $70^{\circ} \mathrm{C}$. The substrate material used is SYRON ${ }^{\mathrm{TM}} 7000$ from Rogers Corporation. It has a thickness of $50.8 \mu \mathrm{m}$ (0.002 inches) and a relative permittivity and loss tangent of $\varepsilon_{\mathrm{r}}=3.4$ and $\tan \delta=0.0045$, respectively. The maximum operating temperature is higher than $210^{\circ} \mathrm{C}$ and the thermal coefficient of the relative permittivity, $\frac{\mathrm{d} \varepsilon_{\mathrm{r}}}{\mathrm{d} T}$ is $+7 \mathrm{ppm} /{ }^{\circ} \mathrm{C}$

The designed CSA layout was simulated and optimized by the use of ANSYS HFSS. The simulated surface current distribution on the slot antenna is shown in Fig. 2.

\section{MEASUREMENT}

The fabricated clover slot antenna was fabricated at the electrical workshop at DTU and thereafter measured in the Spherical Near-field Antenna Test Facility at DTU. The prototype antenna mounted at the tower in the anechoic chamber is shown in Fig. 3. The measured and simulated radiation pattern is seen in Fig. 4. From Fig. 4 it is seen that there is a good agreement between the simulated and measured radiation patterns.

The simulated and measured 10-dB bandwidth is $481 \mathrm{MHz}$ and $585 \mathrm{MHz}$, respectively. As seen from Fig. 5 the simulated antenna is well matched at the $2.45 \mathrm{GHz}$ ISM band. Generally there is good agreement between the measured and simulated values. Table I shows a summary of the results.

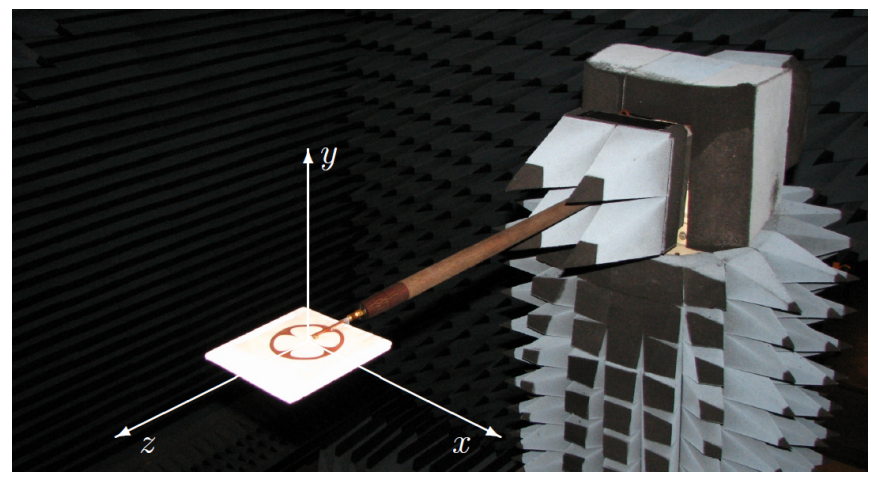

Fig. 3. The prototype CSA in the Spherical Near-field Antenna Test Facility.

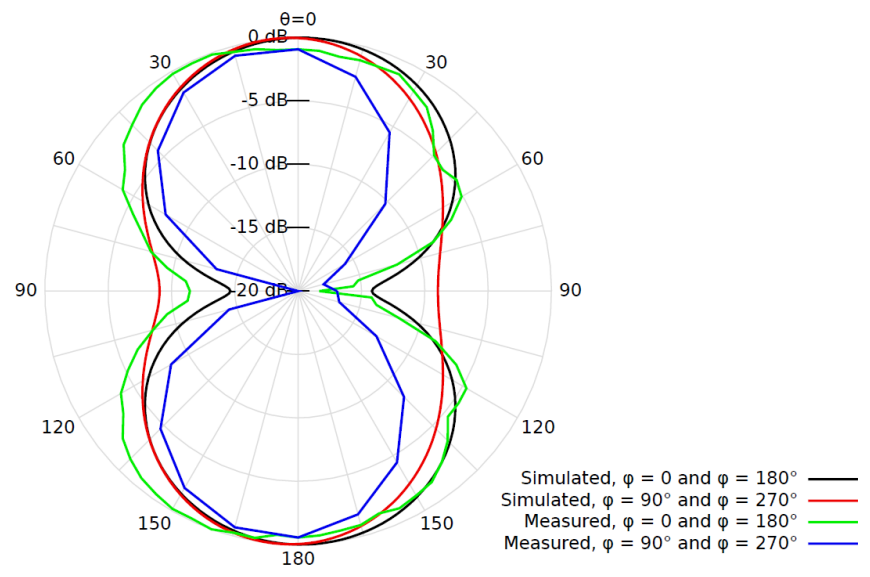

Fig. 4. The simulated and measured radiation patterns of the CSA at 2.4 GHz. The coordinate system is the one shown in Fig. 3.

TABLE I

SUMMARY OF SIMULATED AND MEASURED RESULTS

\begin{tabular}{llllll}
\hline \multirow{2}{*}{ Parameter } & \multicolumn{2}{c}{ HFSS } & & \multicolumn{2}{c}{ Measurement } \\
\cline { 2 - 3 } \cline { 5 - 6 } & $(\mathrm{MHz})$ & $(\%)$ & & $(\mathrm{MHz})$ & $(\%)$ \\
\hline$B W_{10 \mathrm{~dB}}$ & 481 & 16 & & 585 & 20 \\
\hline
\end{tabular}

\section{CONCLUSION}

A clover slot antenna for a SAW sensor based wireless temperature measurement system has been designed for the ISM band at $2.4 \mathrm{GHz}$. Based on the operation environment specification, the primary design criterion has been deduced as robustness against the high ambient temperature and the possibility of oil spills. The temperature resistance requirement has been handled by the selection of the PCB material. Oil spills, on the other hand, like any dielectric-immersed operation, are known to cause an increase in the electrical size of the antenna, and hence a downward shift of the frequency response curve. This issue has been addressed by requiring the design to be wide-band, so that the frequency of operation remains inside the band despite the mentioned downward shift. Based on this decision, the required frequency band has been calculated to be $2.4-3.7 \mathrm{GHz}$. A prototype of the designed antenna has been fabricated and the reflection coefficient and radiation pattern measurements have been made. The simulated and 


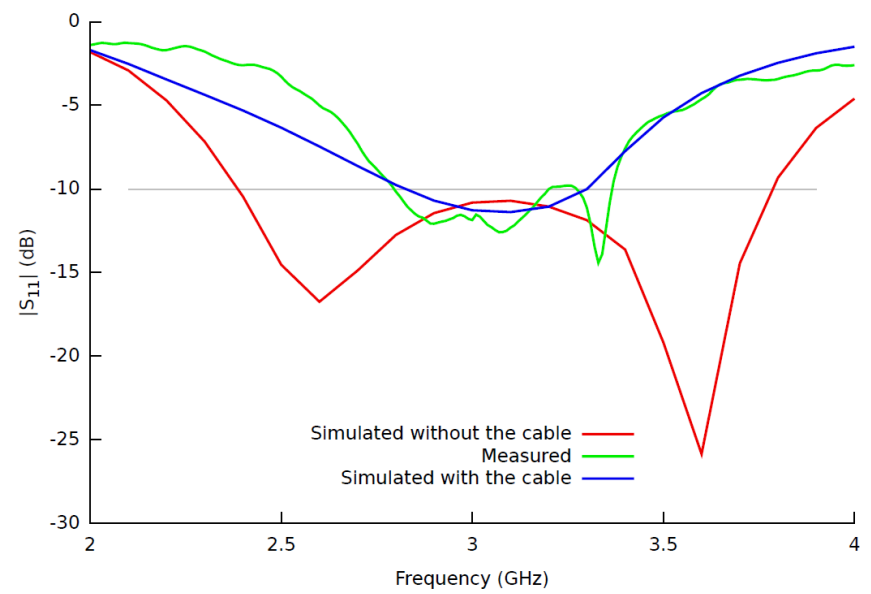

Fig. 5. Reflection coefficient of ... - The $\left|S_{11}\right|$ plots from the earlier simulation, the measurements and the simulation with the cable. The curve obtained from the simulation with the cable is observed to fit significantly better to the measured data.

measured radiation patterns have been seen to be in agreement. The simulation and measurement results shown that the CSA, as a geometrical concept, has the potential to yield a wide frequency-band of operation. This means that the CSA could find use in many applications. The simple and planar design makes it easy and cheap to fabricate. The CSA has been optimized for a chip being soldered onto it, which makes it a desirable type of antenna for RFID applications.

\section{REFERENCES}

[1] A. T. M. Sayem and M. Ali, "Characteristics of a microstrip-fed printed hilbert slot antenna," Progress in Electromagnetics Research, vol. 56, 2006.

[2] W. Lee, H. Kim, and Y. J. Yoon, "A frequency reconfigurable bow-tie slot antenna with wide bandwidth," Microwave and Optical Technology Letters, vol. 50, no. 2, pp. 404-406, 2008.
[3] Y.-L. Zhao, Y.-C. Jiao, G. Zhao, Z.-B. Weng, and F.-S. Zhang, "A novel polarization reconfigurable ring-slot antenna with frequency agility," Microwave and Optical Technology Letters, vol. 51, no. 2, pp. 540-543, 2009.

[4] Y. Sung, "Circularly polarized square ring slot antenna with arrowshaped structure," Etri Journal, vol. 31, no. 5, pp. 506-509, 2009.

[5] Y. Song, Y. C. Jiao, X. M. Wang, Z. Bin Weng, and F. S. Zhang, "Compact coplanar slot antenna fed by asymmetric coplanar strip for $2.45 \mathrm{ghz}$ wlan operations," Microwave and Optical Technology Letters, vol. 50, no. 12, pp. 3080-3083, 2008.

[6] C. Hsieh, T. Chiu, and C. Lai, "Compact dual-band slot antenna at the corner of the ground plane," Ieee Transactions on Antennas and Propagation, vol. 57, no. 10, pp. 3423-3426, 2009.

[7] I. Hossain, S. Noghanian, L. Shafai, and S. Pistorius, "Coplanar waveguide fed taper arc slot antenna for microwave imaging and ultra wide band applications," Microwave and Optical Technology Letters, vol. 51, no. 11, pp. 2607-2611, 2009.

[8] C.-J. Wang and C.-H. Chen, "Cpw-fed stair-shaped slot antennas with circular polarization," Ieee Transactions on Antennas and Propagation, vol. 57, no. 8, pp. 2483-2486, 2009.

[9] G. Q. Luo, Z. F. Hu, Y. Liang, L. Y. Yu, and L. L. Sun, "Development of low profile cavity backed crossed slot antennas for planar integration," Ieee Transactions on Antennas and Propagation, vol. 57, no. 10, pp. 2972-2979, 2009.

[10] L. Zhang, Y. C. Jiao, Y. L. Zhao, G. Zhao, Y. Song, Z. B. Wong, and F. S. Zhang, "Dual-band cpw-fed double h-shaped slot antenna for rfid application," Journal of Electromagnetic Waves and Applications, vol. 22, no. 8-9, pp. 1050-1055, 2008.

[11] C. Chen and E. K. N. Yung, "Dual-band dual-sense circularly-polarized cpw-fed slot antenna with two spiral slots loaded," Ieee Transactions on Antennas and Propagation, vol. 57, no. 6, pp. 1829-1833, 2009.

[12] L.-Y. Tseng and T.-Y. Han, "Microstrip-fed circular slot antenna for circular polarization," Microwave and Optical Technology Letters, vol. 50, no. 4, pp. 1056-1058, 2008.

[13] W. Choi, J. S. Kim, J. H. Bae, G. Choi, and J. S. Chae, "Near-field antenna for rfid smart shelf in uhf," Ieee Antennas and Propagation Society International Symposium and Ursi National Radio Science Meeting, p. 5171866, 2009.

[14] H. Jafari, M. Deen, S. Hranilovic, and N. Nikolova, "Slot antenna for ultra-wideband applications," IEEE Antennas and Propagation Society, AP-S International Symposium (Digest), pp. 1107-1110, 2006.

[15] Z. Y. Lei, J. W. Zhang, R. Yang, X. Liu, L. Chen, and X. H. Kong, "Design of dual-band dual-sense circularly polarized slot antenna," Progress in Electromagnetics Research C, vol. 43, pp. 41-51, 2013.

[16] T. A. Prevost, "Dielectric properties of natural esters and their influence on transformer insulation system design and performance - an update," 2009 Ieee Power and Energy Society General Meeting, Pes '09, Ieee Power Energy Soc. Gen. Meet., Pes, p. 5275167, 2009. 